hæmaturia, be it observed, clearly showed that we had not put in more blood than the viscular system could hold.

Thus, therefore, it seems that the great benefit of trans. fusion in cases of debility after severe injury is by this case fully rindicated, and that in future it will become one of the recognised res'urces of surgery; that, instead of exposing weakened, almost exhausted, patients to the dangers of secondary amputation, we may by this means save not only the life, but the limb; that we may, in fact, when the patient has exhausted all his own scurces of power, bestow upon him a fresh supply, and start him on his work with new capital.

I cannot conclude without recording $\mathrm{my}$ high appreciation of Dr. Roussel's apparatius. The ingenuity of its plan, the care expended in the choice of material, and the mode of workmanship are all admirable. I must thank Dr. Roussel for his affubility in assisting at this case and in teaching me to thoroughly well understand and manipulate his admirable invention.

George-street, Hanover-square.

\section{THE TREATMENT OF INTERMITTENT OR FEN FEVER BY SALICIN.}

BY W. THOMSON, M.D.,

MRDICAL OFFICER OF HEALTH, CONSULTING SURGBON TO THF PETRRBORODGH INFIRMARY, SURGEON TO THE GREAT NORTHBRN RAILWAY, BTC.

ON making the acquaintance of Dr. Maclagan at Dundee last spring, and discussing the now recognised curative power of this remedy in acute rheumatism, I gave it as my.opinion that we have in salicin a remedy equally energetic in staying or cutting short the paroxysm of ague. I determined that as soon as cases presented them. selves I would give it a fair trial, acting on Dr. Maclagan's suggestions as to its administration in full doses; and I hope that the following cases will prove that the failure of the old-fashioned decoction of willow-bark, both in the hands of the inhabitants in the marshy districts, and of the medical men, was from the want of concentration, or the inability to prescribe a sufficiently large dose.

CASE 1.-R. B-, aged thirty-two, has been twice under my care, first in November, 1875, and secondly in March, 1876, for severe attacks of ague. He was a native of the Isle of Ely, Cambridgeshire; was treated with quinine, and was three weeks in band on both occasions, and that he stated to be a shorter time than usual.

On the 2nd of October, I was sent for to see him at 10 A.M. I found him in bed shaking all over, his teeth chattering, and wearing that uahappy expression of countenance one invariably fiods in these cases. Skin moist and clammy; temperature $103^{\circ}$; pulse 110 , weak and frequent. He had a hot bottle to his feet, and had taken hot port wine without feeling better. I told him I was going to send him a new remedy, and he was to be very particular in following the directions, and noting his feelings after each dose. Thirty grains of salicin to be taken every two hours. I saw him again at $7 \mathrm{P}$ Mr, six hours after the first dose. Temperature $99^{\circ}$; pulse 80 . He said he felt much better. Half an hour after the first powder the chilliness began to abate; four hours after most of the unpleasant feelings had vanished, and he thought he need not go on with the medicine. Ordered to continue the salicin every four hours.

Oet. 3rd.-10 A.m. : Found him up by the fireside, looking weak and tired, but saying he felt comparatively well. I told him to be careful, as next day he might have a relapse.

4th. -10 A.M. : Found him as on my last visit. He, however, told me that at six in the morning he had "s the same old feels" come on, and had it not been for the powders (tmo of which he had taken), he was sure he would have lad a relapse. A powder to be taken night and morning, and to come and see me on the 6th, which he did, looking much better. To stop the medicine after to-day. Seen again on the 8 th, after which he went from home, and when be came back, said he had not had such a short autumnal touch for five years, and asked me for some of the medicine to keep hy bim.

Case 2.-Jane G - aged forty, seen Oct. 10th in bed. Skin wet with perspiration, very shaky, can with difficulty sit up, has been ill every other day for a week. Thirty grains to be taken every two hours until I saw her again, which I did on the morning of the 12th, when she gave mo the following account:- "After the second powder the perspiration stopped, and after the fourth the chilliness had gine and the stiffness in the limbs was much relieved." Next day, as was to be expected, she was comparatively well. Next morning she was surprised to find herself equally so. To stop the medicine in the evening, and only take it again if she has any premonitory symptoms. Four days after she was quite well.

CASE 3 I consider very satisfactory. W. A-, aged seventy-four, has been subject to ague at times for years; has now been six months under treatment, quinine having been administered in full doses, until he vows he will take no more, as he believes he feels worse after it. Nitromuriatic acid agreed better. The paroxysms of ague occurred every three or four days, and generally three times a day. As the nest would be his bad day, I ordered him to begin the salicin at once (thirty grains every two hours, if awake). Saw him at 4 P.M. next day. Has had only one fit, and that the powder seemed to stop short; feels and looks much better. To take thirty grains every four hours until after his next bad day; if not well then, to continue the medicine until seen again. Visited on the 9th November, 1876. Said he had a slight feeling of chill on the fourth day after beginning the salicin, but yesterday (the 8tb) felt as well as he does to-day, and that is better than he has done for six months; in fact, he says his limbs are not so stiff as usual, and he walks much better.

As the last two cases were in the Fen, five miles distant, I could not see them sufficiently of ten to note with the thermometer the antipyretic effect, or to record the cases in regular hospital form. I think, however, my first case shows salicin to have an almost magical effect in restoring the equilibrium of the circulation, making normal the temperature and checking this troublesome disease; while my last case shows it to be superior to quinine even in cases of genuine ague of old standing in aged patients.

My excuse for bringing the above cases before the profession without further delay is, that I feel perfectly confident we have in salicin a most valuable remedy, especially in all malarious fevers; and that $I$ am in hopes these remarks may encourage my professional brethren resident in those districts where both willow-bark and fever abound to give it a fair trial and the profession the benefit of their experience.

Westgate, Peterborough.

\section{TWO CASES OF CANCER OF THE KIDNEY.}

\section{BY ANDREW DUNLOP, M.D.}

THe case of cancer of the kidney recorded in THE LANCET of Feb. 10th, by Dr. Andrew, recalls to my mind the two following cases in which the disease ran an upusually slow course.

Mrs. G-, aged fifty, first came under my care on Oct. 8th, 1872. Up to ten or twelve years previously she had enjoyed good health, but she then began to suffer from frequent attacks of severe pain in the left lumbar and inguinal regions, accompanied by vomiting and prostration. Hæmaturia, sometimes copious, also occurred from time to time. Five or six years later the attacks began to diminish in frequency and severity, and then they gradually ceased altogether, and with them the hæmaturia disappeared. But at this time a tumour became perceptible in the left lumbar region anteriorly, and this had gone on increasing ever since. From the date of the appearance of the tumour she had continued weak, with night-sweats and frequent vomiting. The urine was often scanty, but there was never anything unusual in its appearance. During the three months previous to her coming under my care she had lost much flesh, and had got rapidly weaker. 
Symptoms on Oct. 8th, 1872.-Complexion of a sallow, Jellowish tint; tongue clean; appetite small; frequent vomiting; bowels irregular. Somewhat harsh breathing over both lungs posteriorly; slight cough. An indistinct systolic bruit at the apex of the heart; pulse 80 , weak. Had ceased menstruating. Urine rather scanty, containing a trace of albumen, and exbibiting under the microscope a few cells of renal epithelium and some urates. On examining the abdomen, a rounded tumour was found occupying part of the inguinal and the lumbar and hypochondriac regions on the left side. Its rounded lower end was felt some two or three inches below the level of the anterior superior spine of the ilium, and thence it extended upwards till it passed under the ribs, which were somewhat pushed outwards by it. By percussion it was ascertained that its upper margin was on a level with the lower end of the sternum. Inwards it extended as far as the middle line. It was painless on pressure, rather elastic to the touch, and here and there obscurely nodulated. The descending colon passed over it, and in the gut could be felt a few scybala.

Progress.-Little alteration took place from the time of her coming under observation until the beginning of December, when severe diarrhoea set in, and she died exhausted on the 11th of the month.

Autopsy, thirty hours after death.-Permission was only given to open the abdomen. On removing the integuments, it was found that the colon, at the junction of its transverse and descending portions, was adherent to the enlarged left kidney, which was also attached to the spleen. On removing the kidney it was found to weigh $82 \mathrm{oz}$. (5 lb. $2 \mathrm{oz})$, and it measured $10 \frac{1}{2}$ in. in length, $5 \frac{1}{4}$ in. in width, and $16 \frac{1}{4}$ in. in circumference. There were one or two large nodules on its surface, and it was so triable at its lower end that a hole was accidentally made in it with the fingers, from which a quantity of yellowish-white pultaceous matter escaped. On section, it was found that not a trace of renal tissue remained, the whole organ being converted into a mass of encephaloid. The upper part was of more consistence, but in the lower third the morbid material had broken down into a pultaceous mass. There was no trace of any calculus. The spleen was small, but perfectly normal. The liver was free from deposit and healthy. The right kidney was normal; some of the mesenteric glands were infiltrated. The uterus was the size of a large orange, and was infiltrated with cancerous (?) material.

Remarks.-From the history, and the long duration of the case, I was at first disposed to think that the early symptoms were caused by the presence of a calculus in the pelvis of the kidney, and that this calculus had become impacted at the top of the ureter, giving rise to pyo-nephrosis, with perhaps the formation of some cheesy matter, and with great enlargement of the organ. This view was strengthened by the somewhat elastic nature of the tumour. Later, how. ever, the rapid wasting and the cachectic hue of the skin led me to conclude that the disease was almost undoubtedly malignant.

Of the second case I can only give a sketch, as, unfortunately, I took few notes, and the post-mortem examination was incomplete. The patient was a male, aged abont fiftyfive, who first came under my care in April, 1870. He then told me that for the last ten years he had been suffering from frequent attacks of hæmaturia. These attacks came on at irregular intervals, but generally every few montbs. Sometimes the hæmorrhage was copious, at other times the amount of blood was only sufficient to stain the urine a deep brown colour. The attacks seemed to come on independently of any exertion. On examination I detected a tumour in the right lumbar region. The patient was otherwise well, though he was rather thin and had a somewhat cachectic look. After this I frequently attended him during his attacks of bæmaturia, in some of which the hremorrhage was very profuse, and lasted for nearly a week. Between the attacks the urine was normal, or contained a little albumen. Meantime the tumour was slowly increasing in aize. At last, in 1874, after a severe and prolonged attack, he did not rally as usual, and from that time he steadily lost strength and flesh. By the beginning of 1875 he could not leave his bed; his appetite was lost, his tongue and lips became red and tender, there was occasional slight diarrhca, his skin was of a yellowish tint, and he was greatly emaciated. There was no further hæmaturia, but the strength continued to ebb away, the muscles wasted to such a degree that he could hardly move his limbs, and at length be died of exhaustion on the 24th August, 1876.

On the following day I was allowed to examine the affected kidney, but the affected kidney only. Its upper end was adherent to the liver. It was $8 \mathrm{in}$. long, and $4 \frac{1}{2}$ in. wide. I had no opportunity of weighing it. Its lower three-fourths, or thereabout, was entirely converted into a rather friable, yellowish-white mass. In the upper fourth there was still some renal tissue remaining. It was of a pale red colour; it was permeated by a certain amount of fibrous tissue, and had scattered throughout it rounded masses of cancerous matter from $\frac{1}{4}$ in. to $\frac{3}{4}$ in. in dia meter. The amount of renal tissue increased, and the proportion of morbid material gradually diminished, from below upwards. The softer material in the lower threefourths seemed to be undergoing fatty degeneration. I do not know whether it was anything more than a mere coin. cidence that the disease was more marked, or apparently of longer standing, in the lower part of the kidney in both these cases.

So far as my own experience goes, and so far as I have been able to ascertain from reported cases, the duration of malignant disease of the kidney is usually of short duration. of the twenty adult cases alluded to by Roherts, eight died within a year, and seven under three years. Yet out of the twenty, one lived four years, three lived six years, and one seven years. Dr. Andrew's case, where the disease lasted fourteen years, and the two just given, where the duration was from ten to twelve years in the first, and about sixteen years in the second, show that occasionally the progress may be much more slow than is generally sup. posed, and this is to be remembered when forming a diagnosis in a doubtful case.

Jersey.

\section{d. attirnor}

\section{HOS PITAL PRACTICE, BRITISH AND FOREIGN.}

Nalla autem est alia pro certo noseendi via, nisi quamplurimas et morborum et dissectionum historias, tum aliorum, tum proprias collectas habere, inter se comparare.-Moreaga I De Sed. et Caus. Morb., lib. iv. Proemium

\section{GUY'S HOSPITAL LYING-IN CHARITY.}

A CASE OF PLACENTA PREVTA; NARROW ESCAPE FROM ASPHYXIA UNDER CHLOROFORM; INTRA-UTERINE RESPIRATION OF THE FOETUS.

(Under the care of Dr. GallabiN.)

THe fact of the establishment of intra-uterine respiration in the subjoined case has an important medico-legal as well as a clinical bearing. Post-mcrtem examination showed that the left lung had been sufficiently expanded by air to float in water, although the foetus had probably died at least three hours before delivery.

For the following notes we are indebted to Mr. J. Brett, M.R.C.S., resident obstetric assistant.

On the afternoon of Feb. 12th, 1877, a woman twenty.five years of age, between the seventh and eighth months of her fourth pregnancy, sent for assistance. Two weeks before she had had a fall on the left side, and the day previous she had received a blow upon the abdomen. All the morning she had been exerting herself in lifting weights, when suddenly, at 1.30 P.M., she felt a sudden gush from the vagina. At least two pints of blood were lost at this time, and the bleeding continued in lesser quantiiy. None had occurred previously during her pregnancy. The woman fainted from loss of blood, and was lifted into bed. When first seen she had a pulse of 130 , extremely weak. No labour pains had commenced; the os was sufficiently dilated to admit one finger; and the edge of the placenta was felt partially occupying the cervical canal. Dr. Galabin was sent for, but was not at home. The membranes were then ruptured, ergot administered, and a watch kept upon the patient. Her condition appeared so hazardous that all 